Suggested citation: Hassan, Q.K. 2018. Lecture note on: Scaling issues in environmental modelling, In Environmental Modelling, Calgary, AB, Canada.

\title{
Environmental Modelling
}

(ENGO 583/ENEN 635)

Lecture Note

on:

Scaling Issues in Environmental Modelling

Dept. of Geomatics Engineering; and Centre for Environmental Engineering Research and Education

Schulich School of Engineering University of Calgary

Review on Last Topics

Except otherwise noted, (02018 Quazi K. Hassan, under a Creative Commons AttributionNonCommercial-ShareAlike license: https://creativecommons.org/licenses/by-nc-sa/4.0/ 
Suggested citation: Hassan, Q.K. 2018. Lecture note on: Scaling issues in environmental modelling, In Environmental Modelling, Calgary, AB, Canada.

\section{Topics of Discussion}

$\circ \quad$ What is scale?

- Observation/measurement scale

- Modelling scale

- Operational scale

- Geographic scale

- Policy scale

- Cartographic scale

- Remarks

- Scaling

- Down-scaling example

- Up-scaling example

- Causes of scale effects

- Scaling sensitivity

$\circ$ Example of scale sensitivity

\section{What is Scale?}

- Scale is an attribute that refers to the magnitude of the event of interest. It is often associated with issues related to spatial and/or temporal dimensions.

- In the field of scientific research, scale can broadly be categorized into the following six groups (Wu and $\mathrm{Li}, 2009$ ):

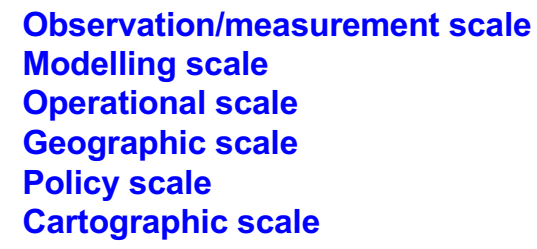

- In the field of remote sensing and its application to environmental modelling, the terms 'scale' and 'resolution' are often used interchangeably. For example:

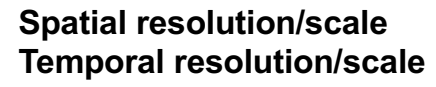


Suggested citation: Hassan, Q.K. 2018. Lecture note on: Scaling issues in environmental modelling, In Environmental Modelling, Calgary, AB, Canada.

\section{Observation Scale}

- It is also known as measurement scale. It can be defined as the scale employed to collect measurements or observations in relation to an event of interest.

- Such observation/measurement scale corresponds to the spatial and/or temporal extent of a dataset. The spatial dimension is critical to geospatial modelling.

- It is very important that the observation scale should match the operational scale for a better comprehension of the issue of interest.

\section{Modelling Scale (1)}

- It is also known as working scale. At this scale, an environmental model is constructed.

- The modeling scale should agree with both the observation/measurement and operational scale.

- In case of hydrological models:

- The spatial resolution can be at local/plot scale, the catchment scale, and the regional scale.

○ On the contrary, the temporal resolution can be daily, weekly, bi-monthly, monthly, annually, and so on. 
Suggested citation: Hassan, Q.K. 2018. Lecture note on: Scaling issues in environmental modelling, In Environmental Modelling, Calgary, AB, Canada.

\section{Modelling Scale (2)}

- The modelling scale primarily relies on both spatial and temporal resolution of an environmental process.

For example, coastal planners and managers are mainly interested in the range of scales indicated by the dashed box.

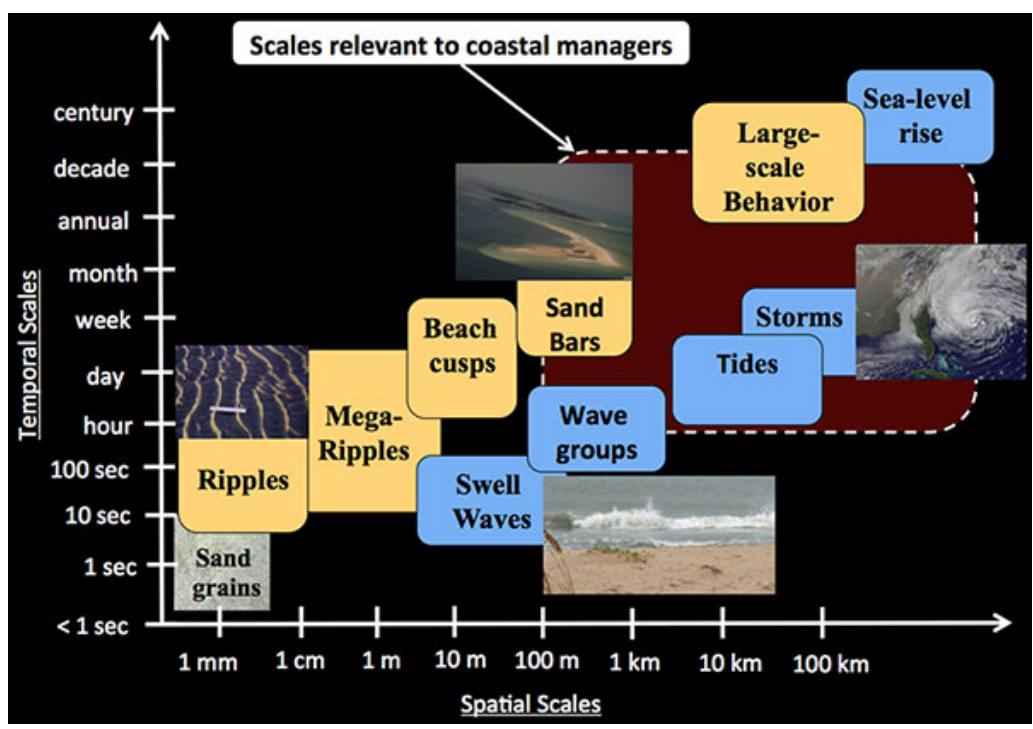

Credit: U.S. Geological Survey;

https://marine.usgs.gov/coastalchangehazards/research/data-integration.html

\section{Operational Scale}

- It is also known as process scale. It can be defined as the scale at which a particular process is supposed to take place.

- This scale is connected with the spatial and temporal resolution depending on the nature of the process. For example:

- Agricultural crop growth within a 1-3 day interval from sowing to maturitylevel for a particular crop of interest;

- Hurricane between a 15-30 minute interval, in order to find the direction and magnitude of its movement.

- Thus, an environmental phenomenon is best observed/measured at its operational scale. 
Suggested citation: Hassan, Q.K. 2018. Lecture note on: Scaling issues in environmental modelling, In Environmental Modelling, Calgary, AB, Canada.

\section{Geographic Scale (1)}

- Geographic scale is the related to the physical size or spatial extent of the study area.

- A large geographic scale deals with a larger area,

- i.e., the Province of Alberta

- A small geographic scale covers a smaller area.

- i.e., Calgary Region

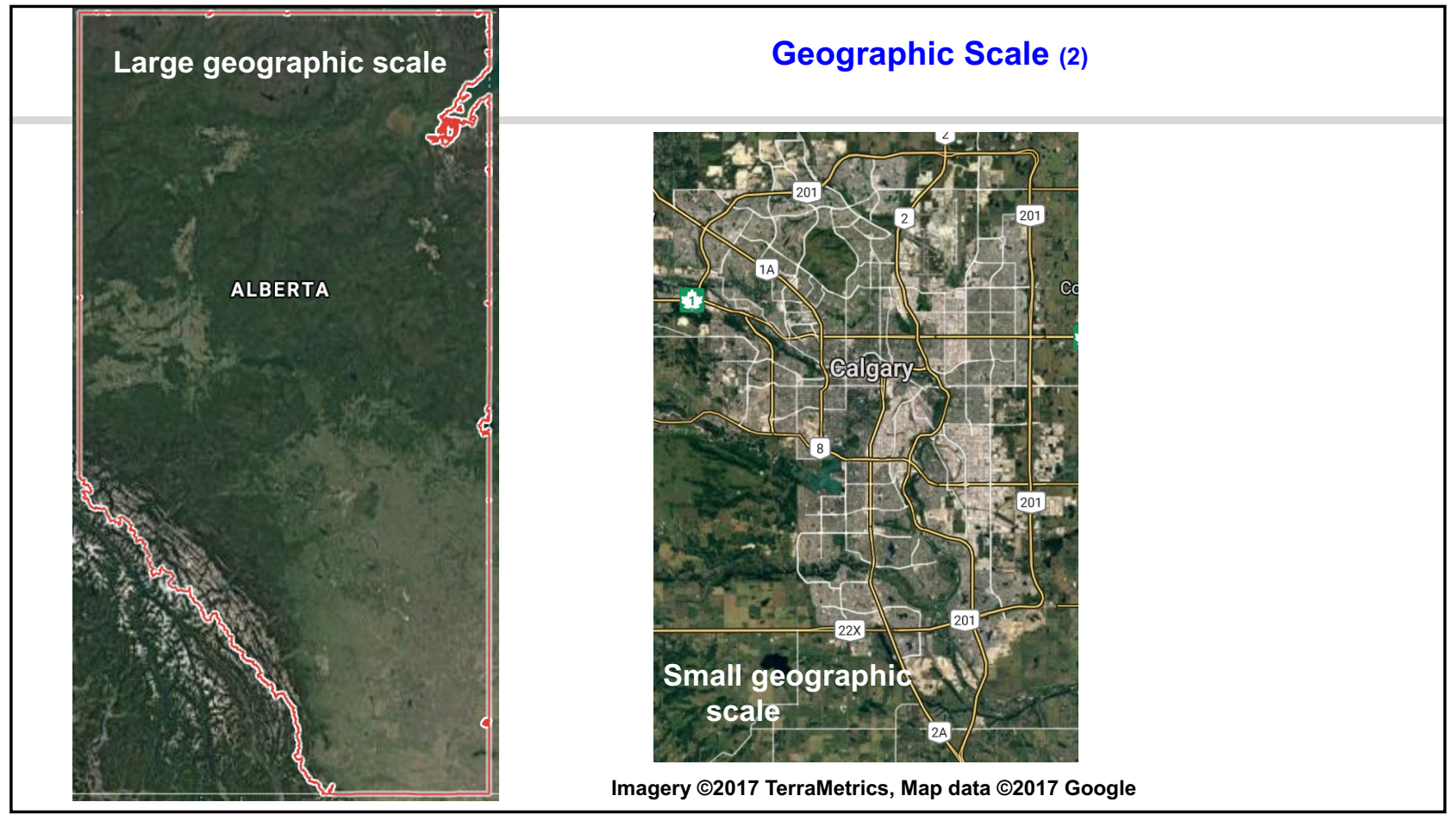

Except otherwise noted, (02018 Quazi K. Hassan, under a Creative Commons AttributionNonCommercial-ShareAlike license: https://creativecommons.org/licenses/by-nc-sa/4.0/ 
Suggested citation: Hassan, Q.K. 2018. Lecture note on: Scaling issues in environmental modelling, In Environmental Modelling, Calgary, AB, Canada.

\section{Policy Scale}

- Policy scale is often associated with the jurisdiction at which a decision is taken for implementation.

- Such policy scale can be formulated and implemented at various level depending on the nature of the issue. For example:

○ Climate change policy: global level

Immigration and citizenship: country level

- Education and health care: provincial/state level in Canada and US

○ Land use zonation policy: municipality level

\section{Cartographic Scale}

- It represents the ratio between the distance on a map and to the corresponding distance on the ground or reality.

- A large scale map refers to a smaller area that provides detailed information over an area of interest:

- i.e., scale 1: 10000 (this is a commonly used scale to generate base maps across the world)

- On the contrary, a small scale map refers to a larger area that provides coarser information about the area of interest:

- i.e., scale 1: 250000 
Suggested citation: Hassan, Q.K. 2018. Lecture note on: Scaling issues in environmental modelling, In Environmental Modelling, Calgary, AB, Canada.

\section{Remarks}

- When implementing an environmental model, a modeller must consider the following four scales:

- Geographic scale of the study area

- Temporal scale related to the time period of the research

- Observation/measurement scale of parameters

- Model scale associated with both spatial and temporal resolution

- In ecological modelling, the ecologists often mention 'scale' as grain and extent

- grain relates to the smallest spatial sampling (i.e., spatial resolution)

o extent relates to the total area over (i.e., geographic scale)

\section{Scaling}

- Scaling is the act of transferring data/information from one scale to another

- It focuses on what happens to the characteristics of an object or a system when its scale is changed

- Downscaling is the act of transferring data from a coarse resolution to a fine resolution upon exploiting knowledge at coarser scale

- Upscaling is the act of transferring data from a fine resolution to a coarse resolution based on extrapolated knowledge at finer scale

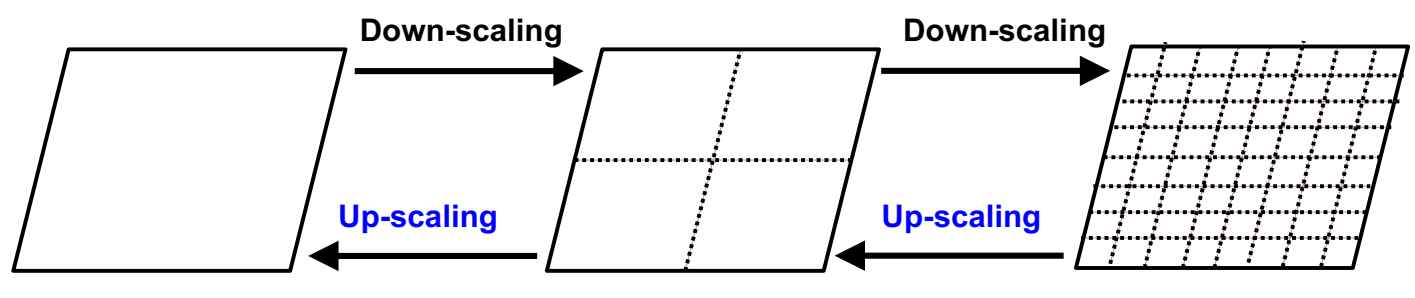

Coarse resolution

Medium resolution

Fine resolution 
Suggested citation: Hassan, Q.K. 2018. Lecture note on: Scaling issues in environmental modelling, In Environmental Modelling, Calgary, AB, Canada.

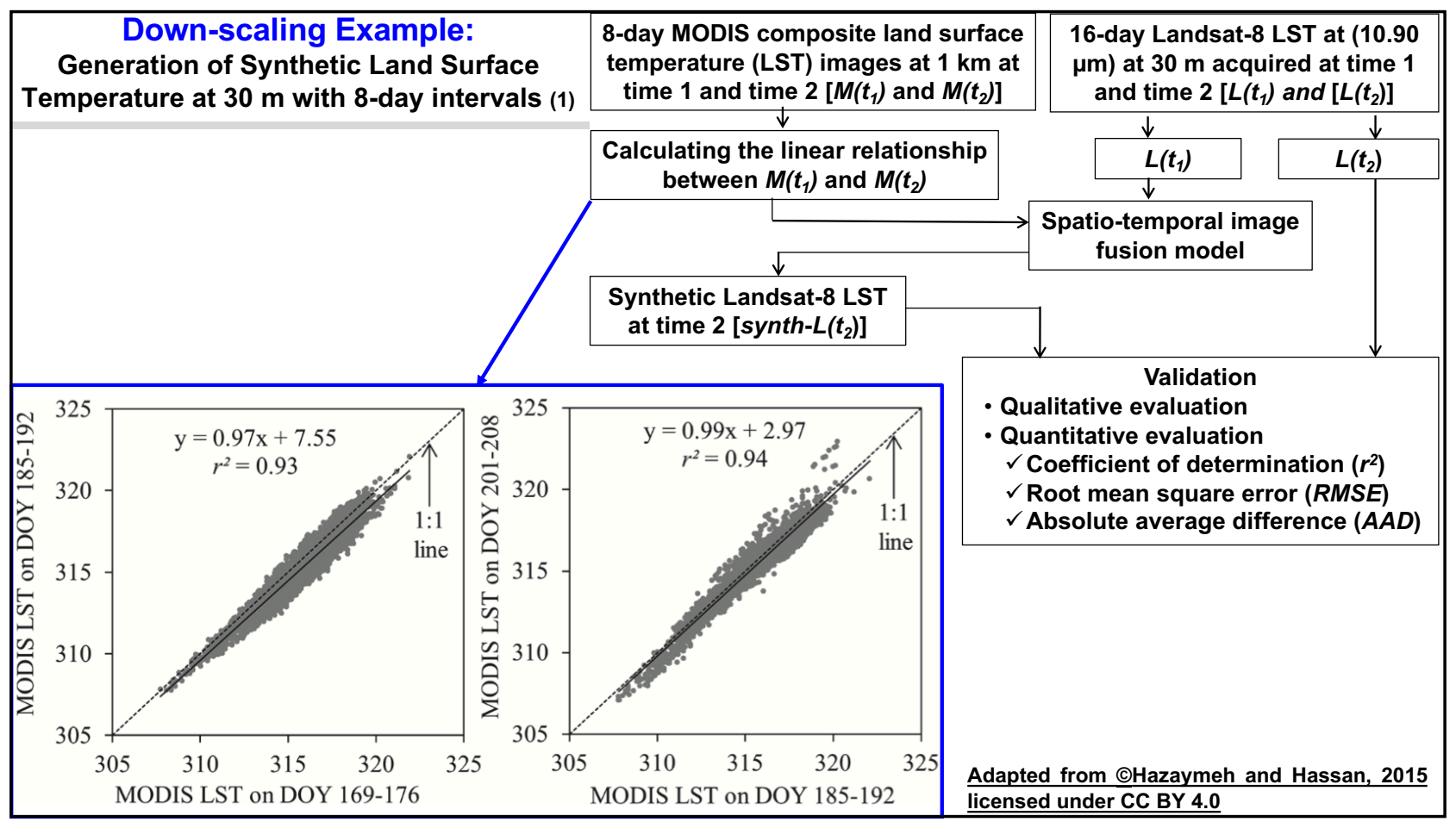

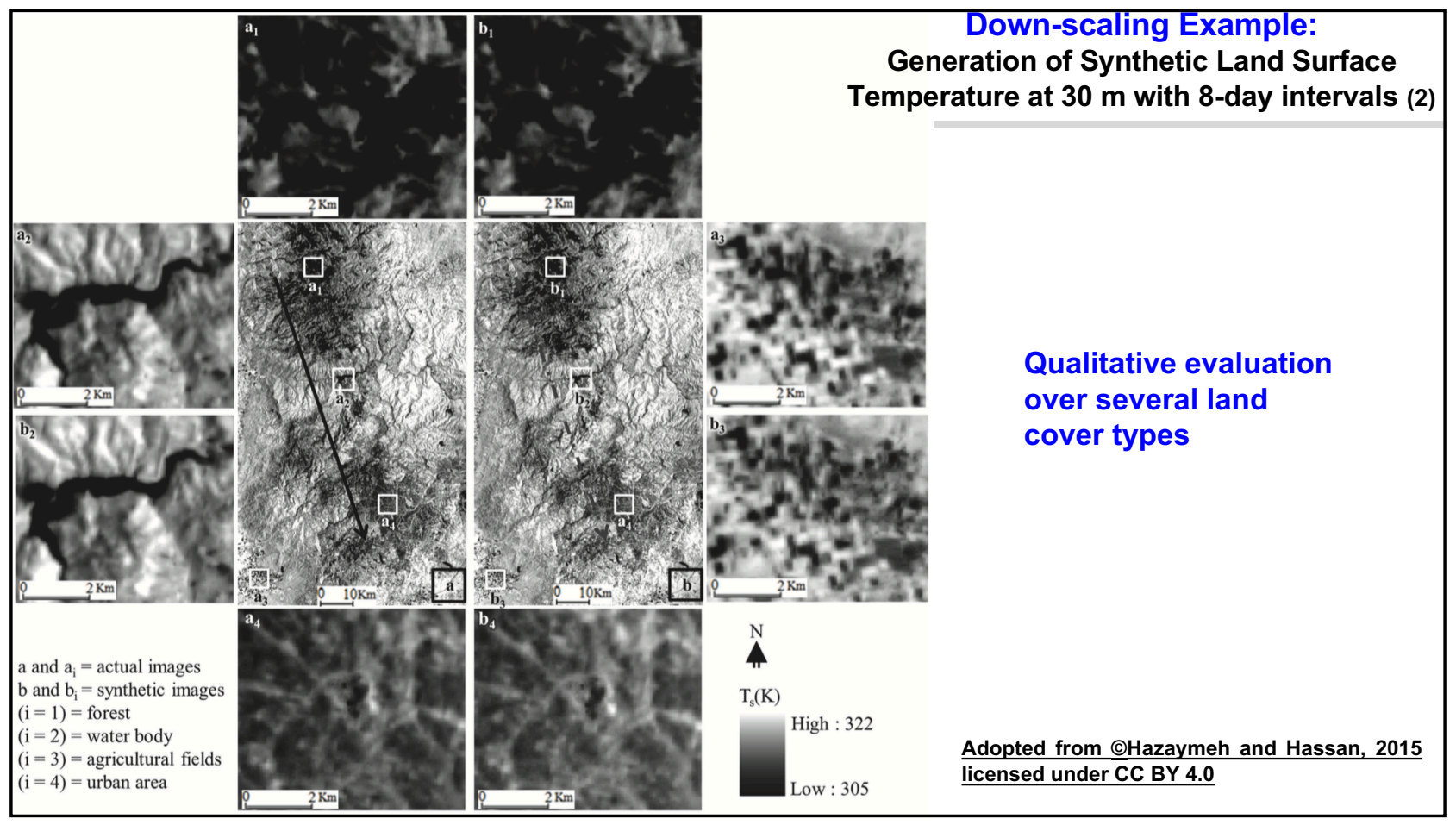

Except otherwise noted, (02018 Quazi K. Hassan, under a Creative Commons AttributionNonCommercial-ShareAlike license: https://creativecommons.org/licenses/by-nc-sa/4.0/ 
Suggested citation: Hassan, Q.K. 2018. Lecture note on: Scaling issues in environmental modelling, In Environmental Modelling, Calgary, AB, Canada.
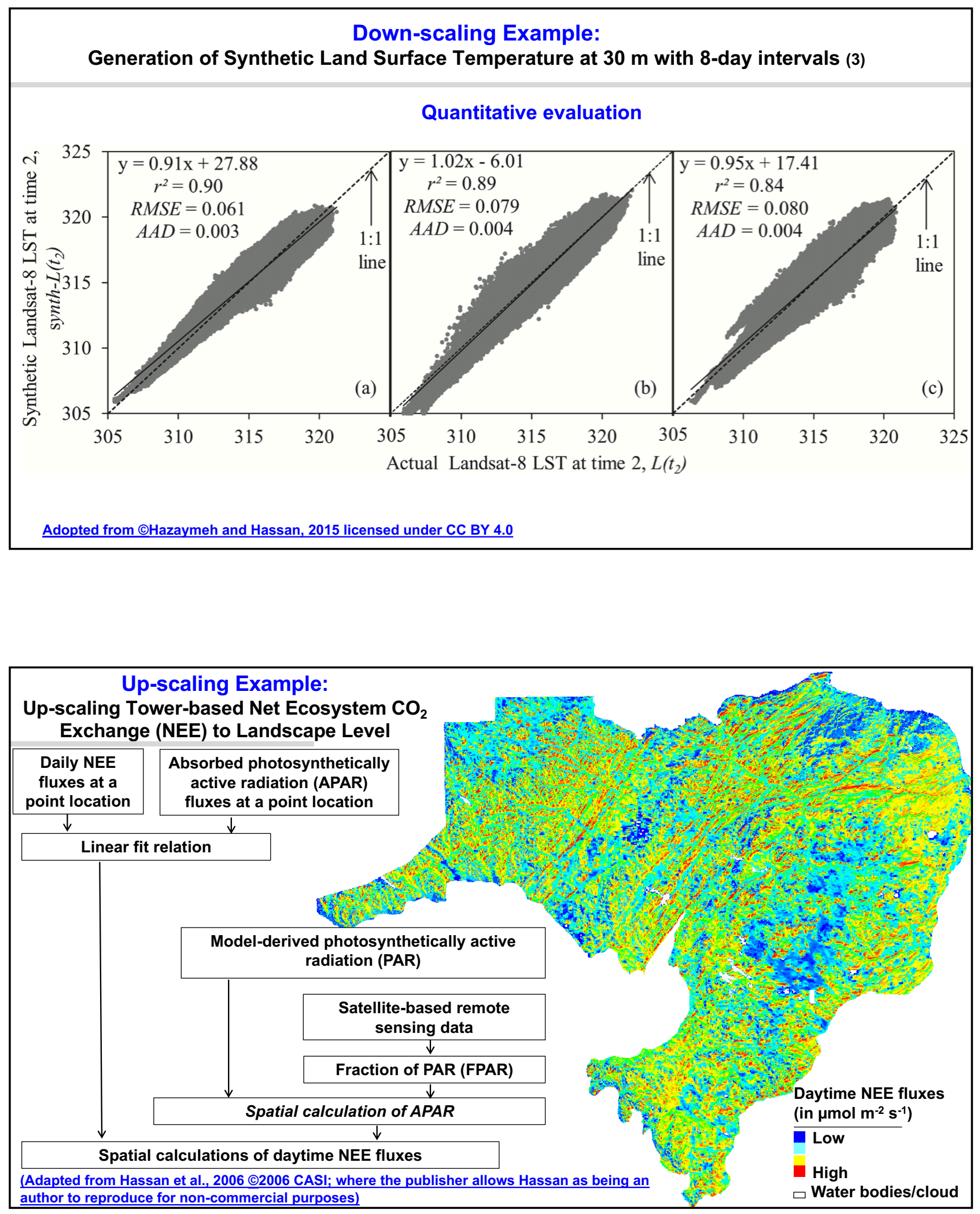

Except otherwise noted, (2018 Quazi K. Hassan, under a Creative Commons AttributionNonCommercial-ShareAlike license: https://creativecommons.org/licenses/by-nc-sa/4.0/ 
Suggested citation: Hassan, Q.K. 2018. Lecture note on: Scaling issues in environmental modelling, In Environmental Modelling, Calgary, AB, Canada.

\section{Causes of Scale Effects}

Wu and Li (2009) summarized three main reasons behind the scale effect as follows:

i. Limitation of measurement relates to the fact that equipment can only acquire information at a particular scale. For example: a hand-held spectroradiometer provides reflection regimes from a small area, on the other hand the satellite-based ones provide the same over a relatively large area.

ii. Applicability of a given relationship across the various spectra, e.g., a model at the scale of one tree may not be applicable to the stand-scale. Thus, we may have to revisit the model when applying to any other scale apart from the originally proposed one.

iii. Existence of both spatial heterogeneity and relevant process nonlinearities, e.g., temperature varies in both spatial and temporal dimensions. In general, temperature is primarily defined by the incident solar radiation; however, land cover types also influence its magnitude.

\section{Scaling Sensitivity}

In general, the magnitude of a given parameter in an heterogeneous environment is usually dependent on the measurement scale

- These parameters are called to be scale dependent, such as the measurement of soil water content

- If the parameter values do not change significantly across a range of scales, this parameter is said to be scale invariant, e.g.,

- reflection from fresh snow measured at any scale 
Suggested citation: Hassan, Q.K. 2018. Lecture note on: Scaling issues in environmental modelling, In Environmental Modelling, Calgary, AB, Canada.

\section{Example of Scale Sensitivity (1)}

$\circ \quad$ Feng et al. (2015) used unmanned aerial vehicle (UAV)-based remote sensing images to evaluate the effect of up-scaling on the overall accuracy of the classification.

- The original spatial resolution of these images was $7 \mathrm{~cm}$. Then Feng et al. (2015) employed nine different moving windows to analyze how classification accuracy changes. These texture window size included:

○ $3 \times 3,5 \times 5,7 \times 7,9 \times 9,11 \times 11,15 \times 15,21 \times 21,31 \times 31$, and $51 \times 51$.

The targeted classes were: grass, trees, shrubs, bare soil, water, and impervious surface.

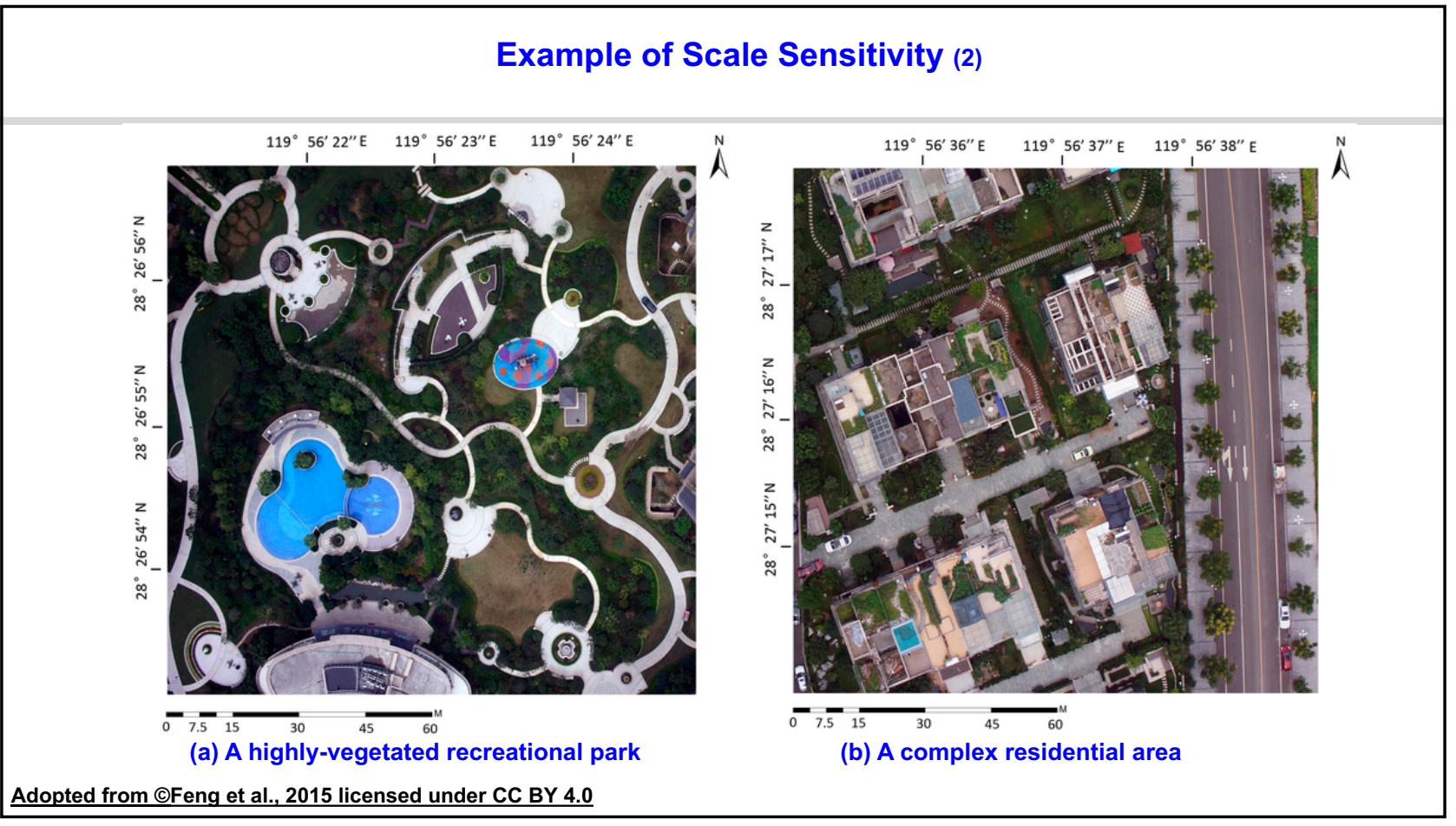

Except otherwise noted, (02018 Quazi K. Hassan, under a Creative Commons AttributionNonCommercial-ShareAlike license: https://creativecommons.org/licenses/by-nc-sa/4.0/ 
Suggested citation: Hassan, Q.K. 2018. Lecture note on: Scaling issues in environmental modelling, In Environmental Modelling, Calgary, AB, Canada.

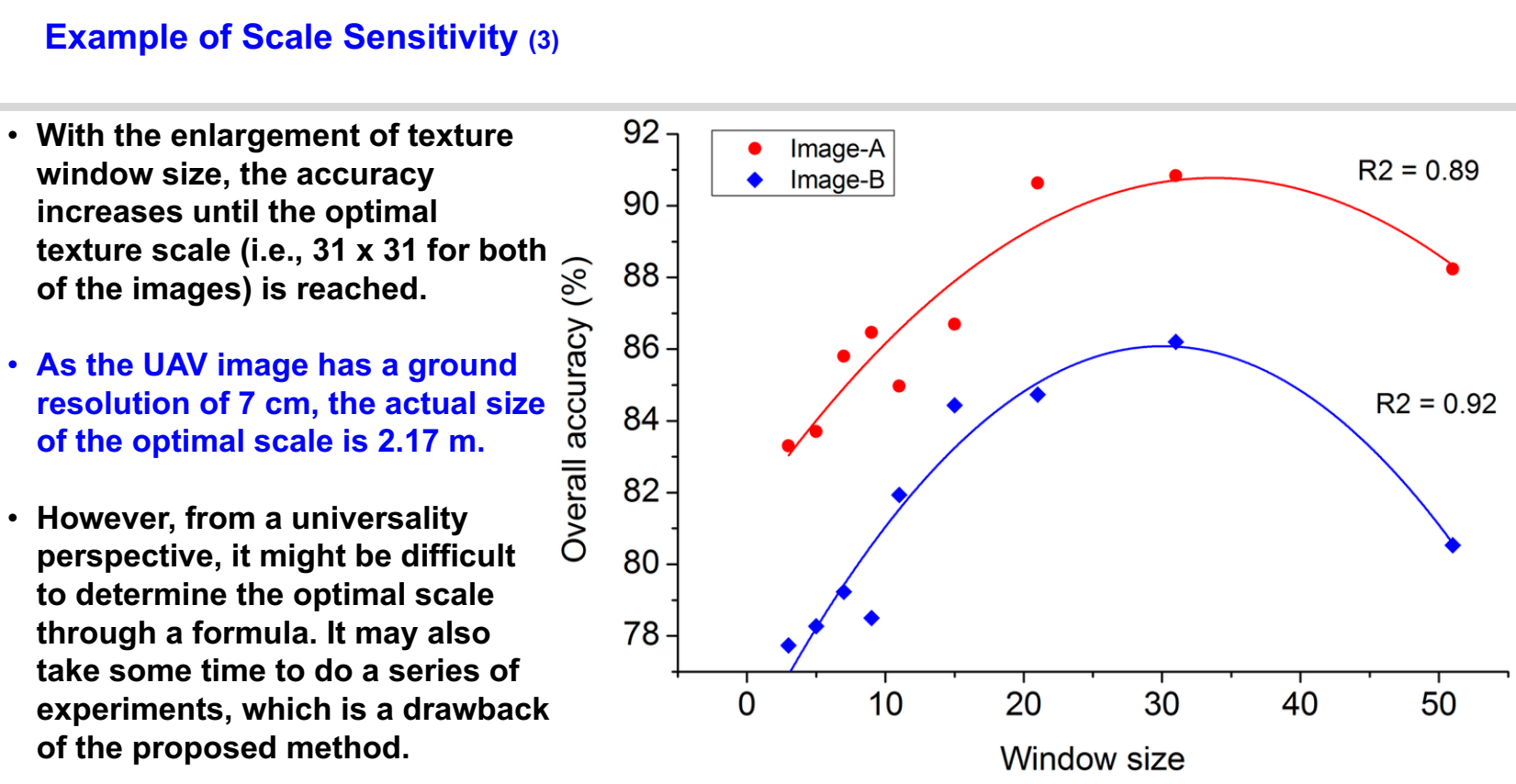

Adopted from $\odot$ Feng et al., 2015 licensed under CC BY 4.0

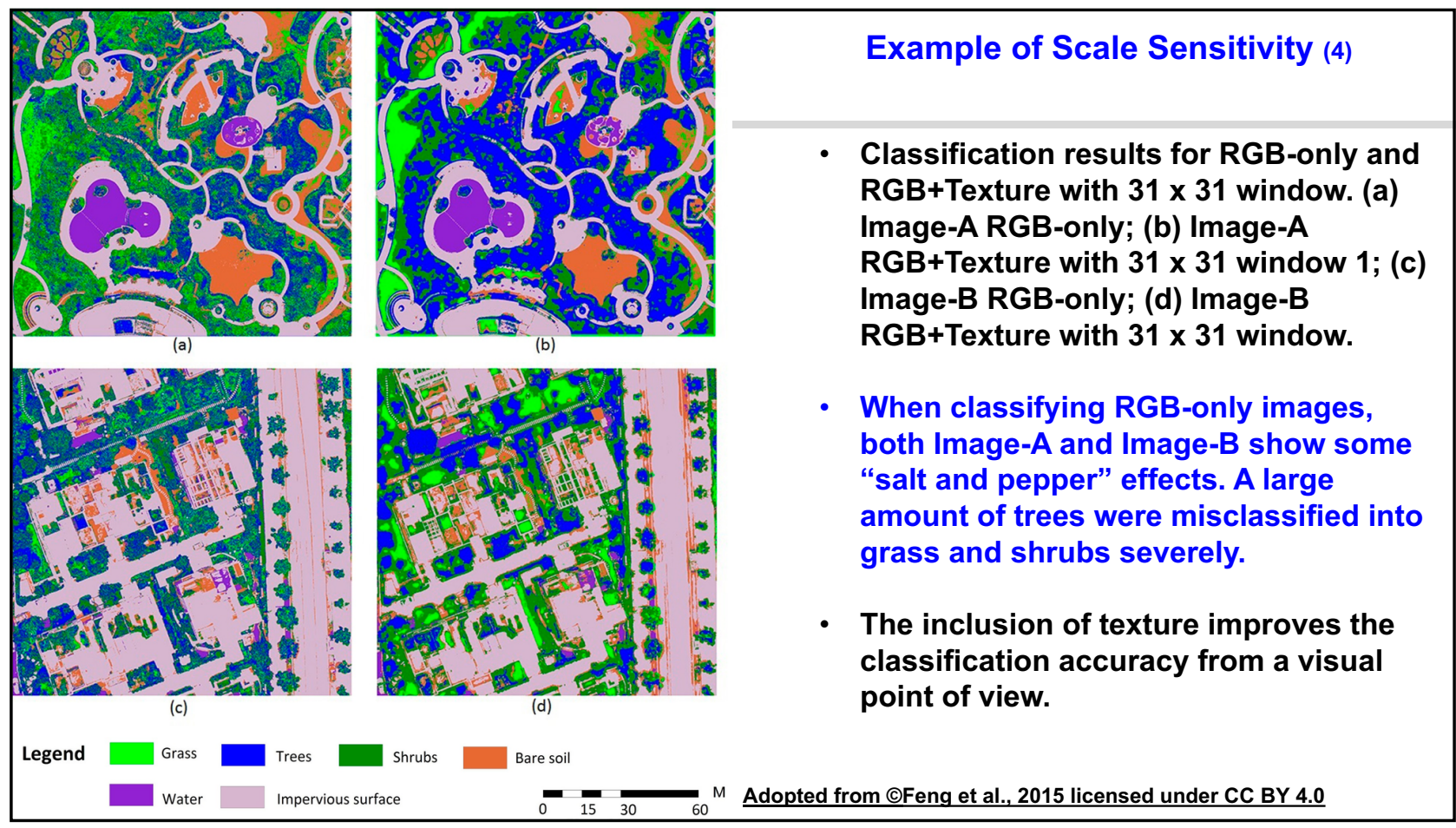

Except otherwise noted, (02018 Quazi K. Hassan, under a Creative Commons AttributionNonCommercial-ShareAlike license: https://creativecommons.org/licenses/by-nc-sa/4.0/ 
Suggested citation: Hassan, Q.K. 2018. Lecture note on: Scaling issues in environmental modelling, In Environmental Modelling, Calgary, AB, Canada.

\section{References}

○ Feng, Q., Liu, J., Gong, J. (2015) UAV Remote Sensing for Urban Vegetation Mapping Using Random Forest and Texture Analysis. Remote Sensing, 7, 1074-1094.

- Hassan, Q.K., Bourque, C.P.-A., Meng, F.-R. (2006) Estimation of daytime net ecosystem CO2 exchange over balsam fir forests in eastern Canada: combining averaged towerbased flux measurements with remotely sensed MODIS data. Canadian Journal of Remote Sensing, 32, 405-416.

$\circ$ Hazaymeh, K., Hassan, Q.K. (2015) Fusion of MODIS and Landsat-8 surface temperature images: A new approach. PLoS One, 10, e0117755.

○ Wu, H., Li, Z.-L. (2009) Scale Issues in Remote Sensing: A Review on Analysis, Processing and Modeling. Sensors, 9, 1768-1793.

\section{Sample Review Questions}

- Define scale. What are the commonly used meanings of scale in environmental modelling? Provide examples.

- Define scaling. Describe the basis of both up-scaling and down-scaling in environmental modelling. Provide example for each of the cases.

-What are the causes of scale effects?

$\circ$ What is the difference between scale dependent and scale invariant?

- What is scale sensitivity? Consider an environmental model is given. Determine the type of scaling and comment on the results of performing certain scaling. 